\title{
WAS GAUNILO RIGHT IN HIS CRITICISM OF ANSELM? A CONTEMPORARY PERSPECTIVE
}

\section{JAN WOLEŃSKI}

Jagiellonian University

\begin{abstract}
Gaunilo argued that Anselm could prove the existence of many perfect objects, for example, the happiest island, that is, happier than any other island. More formally, Gaunilo's arguments were intended to show that the sentence "God exists" does not follow from premises accepted by Anselm. Contemporary versions of the ontological proof use the maximalization procedure in order to demonstrate that God exists as the most perfect being. This paper argues that this method, which is based on maximalization, is not sufficient to prove God's existence. Thus, a "contemporary Gaunilo" can repeat objections raised by his ancestor.
\end{abstract}

Gaunilo, a Benedictine monk (who lived in the years 1033-1011, mostly in the Marmoutier Abbey in France), offered the first criticism of St. Anselm's ontological proof of God's existence in a small booklet Liber pro insipiente (On Behalf of the Fool). The title alludes to the words "How the Fool said in his heart which cannot be said" at the beginning of Chapter IV of Anselm's Proslogion (written in 1077-1078). ${ }^{1}$ Although this phrase is a rather pejorative piece of rhetoric, Gaunilo took it as innocent and formulated arguments defending the Fool. The text of Liber pro insipiente was added to Proslogion together with Anselm's reply. ${ }^{2}$ My aim in this

\footnotetext{
${ }^{1}$ I quote the Proslogion from Anselm of Canterbury's, Complete Philosophical and Theological Treatises, tr. by J. Hopkins and H. Richardson (Minneapolis: The Arthur J. Benning Press, 2000), pp. 88-112.

${ }^{2}$ I quote the texts that constitute these polemics from the 'Internet History Sourcebooks Project', tr. by S. Deane, ed. by P. Halsall, http://evans-experientialism.freewebspace.com/ gaunilo.htm [accessed 11th June 2012].
} 
paper is to evaluate the Gaunilo/Anselm exchange from a contemporary (logical) perspective. Roughly speaking, I will play the role of a "modern Gaunilo". Since Gaunilo did not refer to Monologion, Anselm's earlier work, I will not mention this work either. In fact, since Proslogion continues and improves upon Monologion, restricting my discussion to the former is justified from a systematic point of view also.

The relevant text from Anselm's Proslogion runs as follows (excerpts from pp. 93-95):

\section{CHAPTER TWO}

God truly [i. e. really] exists. [...].

Indeed, we believe You to be something than which nothing greater can be thought. Or is there, then, no such nature [as You], for the Fool has said in his heart that God does not exist? But surely when this very same Fool hears my words "something than which nothing greater can be thought", he understands what he hears. And what he understands is in his understanding, even if he does not understand [i.e. judge] it to exist. For that a thing is in the understanding is distinct from understanding that [this] thing exists. [...] So even the Fool is convinced that something than which nothing greater can be thought is at least in his understanding; for when he hears of this [being], he understands [what he hears], and whatever is understood is in the understanding. But surely that than which a greater cannot be thought cannot be only in the understanding. For if it were only in the understanding, it could be thought to exist also in reality - something which is greater [than existing only in the understanding]. Therefore, if that than which a greater cannot be thought were only in the understanding, then that than which a greater cannot be thought would be that than which a greater can be thought! But surely this [conclusion] is impossible. Hence, without doubt, something than which a greater cannot be thought exists both in the understanding and in reality. [...].

\section{CHAPTER THREE}

[God] cannot be thought not to exist.

Assuredly, this [being] exists so truly [i.e. really] that it cannot even be thought not to exist. For there can be thought to exist something which cannot be thought not to exist; and this thing is greater than that which can be thought not to exist. Therefore, if that than which a greater cannot be thought could be thought not to exist, then that than which a greater cannot be thought would not be that than which a greater cannot be thought - [a consequence] which is 
contradictory. Hence, something than which a greater cannot be thought exists so truly that it cannot even be thought not to exist. And You are this [being] [...]. Therefore, [...] You exist so truly that You cannot even be thought not to exist. And this is rightly the case. For if any mind could think of something better than You, the creature would rise above the Creator and would sit in judgment over the Creator - something which is utterly absurd. Indeed, except for You alone, whatever else exists can be thought not to exist. Therefore, You alone exist most truly of all and thus most greatly of all; for whatever else exists does not exist as truly [as do You] and thus exists less greatly [than do You]. Since, then, it is so readily clear to a rational mind that You exist most greatly of all, why did the Fool say in his heart that God does not exist?! - why [indeed] except because [he is] foolish and a fool!

\section{CHAPTER FOUR}

How the Fool said in his heart that which cannot be thought.

Yet, since to speak in one's heart and to think are the same thing, how did [the Fool] say in his heart that which he was unable to think, or how was he unable to think that which he did say in his heart? Now, if he truly [i.e. really] - rather, since he truly - both thought [what he did] because he said [it] in his heart and did not say [it] in his heart because he was unable to think [it], then it is not the case that something is said in the heart, or is thought, in only one way. For in one way a thing is thought when the word signifying it is thought, and in another way [it is thought] when that which the thing is is understood. Thus, in the first way but not at all in the second, God can be thought not to exist. Indeed, no one who understands that which God is can think that God does not exist, even though he says these words [viz. "God does not exist"] in his heart either without any signification or with some strange signification. For God is that than which a greater cannot be thought. Anyone who rightly understands this, surely understands that that [than which a greater cannot be thought] exists in such way that it cannot even conceivably not exist. Therefore, anyone who understands that God is such [a being] cannot think that He does not exist. [...].

Omitting rhetorical accents, Anselm's argument can be segmented into several steps:

(1) It is possible to imagine a being than which none greater can be conceived.

(2) Existence in reality is greater than existence in the mind alone.

(3) If any imagined being exists only in the human mind, it is not a "being than which none greater can be conceived". 
(4) Any being than which none greater can be conceived must also exist in reality.

(5) The lack of existence in reality would mean the failure to be a being than which none greater can be conceived.

(6) Consequently, the being than which none greater can be conceived must exist, and we truly call this being God.

In fact, Anselm argues that if one can imagine God as the being which is greater than any other being, the predicate "is God" is not empty. Anselm's demonstration goes via reductio ad absurdum and tries to establish God's existence on the basis of the assertion "it is impossible to conceive the predicate 'is God' as empty".

Gaunilo agrees that we can imagine something which is greater than any other being and debate about such items, in particular about their existence. Similarly, we can imagine items which have no counterparts in the actual world. Surely, we understand related locutions. However, according to Gaunilo, these observations do not lead to any definite existential conclusions. Gaunilo applies this observation to the being which is greater than any other being (here "in the understanding" means "in mind"):

But that this being must exist, not only in the understanding but also in reality, is thus proved to me:

If it did not so exist, whatever exists in reality would be greater than it. And so the being which has been already proved to exist in my understanding, will not be greater than all other beings.

I still answer: if it should be said that a being which cannot be even conceived in terms of any fact, is in the understanding, I do not deny that this being is, accordingly, in my understanding. But since through this fact it can be no wide attain to real existence also, I do not concede to it that existence at all, until some certain proof of it shall be given.

For he who says that this being exists, because otherwise the being which is greater than all will not be greater than all, does not attend strictly enough to what he is saying. For I do not yet say, no, I even deny or doubt that this being is greater than any real object. Nor do I concede to it any other existence (if it should be called existence) which it has when the mind, according to a word merely heard, tries to form an image of an object absolutely unknown to me. [...]. 
[I]t should be proved first that this being itself really exists somewhere; and then, from the fact that it is greater than all, we shall not hesitate to infer that it also subsists in itself.

[...] For example: it is said that somewhere in the ocean is an island, which, because of the difficulty, or rather the impossibility, of discovering what does not exist, is called the Lost Island. And they say that this island has an inestimable wealth of all manner of riches and delicacies in greater abundance than is told of the islands of the blest; and that having no owner or inhabitant, it is more excellent than all other countries, which are inhabited by mankind, in the abundance with which it is stored.

Now if someone should tell me that there is such an island, I should easily understand his words, in which there is no difficulty. But suppose that we went on to say, as if by a logical inference: "You can no longer doubt that this island which is more excellent than all lands exists somewhere, since you have no doubt that it is in your understanding. And since it is more excellent not to be in the understanding alone, but to exist both in the understanding and in reality, for this reason it must exist. For if it does not exist, any land which really exists will be more excellent than it; and so the island already understood by you to be more excellent will not be more excellent.

If a man should try to prove to me by such reasoning that that this island truly exists, and that its existence should be no longer be doubted, either I should believe that he was jesting, or I know not which I ought to regard as the greater fool; myself, supposing that I should allow this proof; or him, if he should suppose that that he had established with any certainty that existence of this island. For he ought to show first that the hypothetical excellence of this island exists as a real and indubitable fact, and in no wise as any unreal object, or one whose existence is uncertain, in my understanding.

Thus, Gaunilo argues that conceiving something as greater than anything else does not imply that the imagined objects exists. In fact, Gaunilo rejects two conclusions. Firstly, that the item in question must exist (a stronger assertion), and secondly, that it exists (a weaker assertion). Generally, according to Gaunilo, being in the understanding (mind) does not entail an assertion of existence. Yet he did not intend to prove that God does not exist, but only to demonstrate that Anselm's argument is not valid. 
St. Anselm counterattacked Gaunilo's objections immediately and tried to show that his criticism fails. He repeated his demonstration in the following way:

[...] if that [i.e. that which is greater than any other] being can be even conceived to be, it must exist in reality. For that than which a greater is inconceivable cannot be conceived except as without beginning. But whatever can be conceived to exist, and does not exist, can be conceived to exist through a beginning. Hence what can be conceived to exist, but does not exist, is not the being than which is a greater cannot be conceived. Therefore, if such a being can be conceived to exist, necessarily it does exist.

As far as the matter concerns the island which is the most excellent but still unreal (the Lost Island), Anselm points out that it can be conceived as not existing. The Lost Island is essentially different from God, because one cannot imagine the object greater than $\mathrm{He}$ is, although the most excellent land could be still replaced by a more excellent land. Anselm's argumentation, in his reply to Gaunilo, explicitly refers to modalities, because it essentially uses the idea that God's existence is necessary, but the Lost Island and similar items are contingent.

It seems that Gaunilo's criticism of Anselm remained unknown until recent times. Thomas Aquinas, who rejected Anselm's ontological proof in favour of cosmological demonstrations, never mentioned the monk of Marmoutier, although the Doctor Angelicus shared Gaunino's contention that merely conceptual analysis of the essence has no existential consequences. According to Aquinas' view, one must prove God's existence before accepting that essentia implies existentiae in the case of Supreme Being. The Anselm/Gaunilo controversy was also ignored by further ontological attempts to prove God's existence, in particular by Descartes and Leibniz. Kant criticized such proofs by pointing out that existence is not a predicate (is not expressible by a predication), contrary to the tradition from Anselm to Leibniz. Kant, contrary to Aquinas, Descartes, or Leibniz, argued that no theoretical, ontological as well as cosmological, proof of God's existence is available. According to Kant, who was not an atheist, the issue can be solved by practical reason.

Gaunilo's name became fairly popular in the age of modal proofs of God's existence. ${ }^{3}$ I will examine Gaunilo's arguments, or rather formulate

3 See J. H. Sobel, Logic and Theism: Arguments for and against Beliefs in God (Cambridge: Cambridge University Press, 2004) for an extensive and penetrating survey. 
Gaunilo-like arguments, in a more contemporary setting. Before doing so, I will repeat his reasons as well as Anselm's reply in another language. Gaunilo proposed to introduce a predicate $P$ defined by the phrase "consistently possesses properties $F$ to the greatest degree than other objects", for example the Lost Island, mountains higher than all known peaks, or persons taller than all people who already exist or will exist in the future. Gaunilo's next step consists in demonstrating that Anselm's inference sometimes leads to true conclusions, but some arguments end with false propositions. If so, we have a simple way to argue that there are items which do not exist. This means that Anselm's proof is not conclusive, that is, its conclusion does not follow from the assumed premises. Once again, this criticism does not lead to the assertion that God does not exist, but qualifies Anselm's proof as formally fallacious. Gaunilo claimed that Anselm showed that the denotation of $P$ exists in the mind only. Hence, it must be supplemented by demonstration that it exists in the world as well. Anselm's strategy points out that in some cases, for example, with respect to the Lost Island, we can say either that $P$ is empty or that it is non-void. On the other hand, the denotation of the predicate "is God" is necessarily non-empty.

Anselm's understanding of necessity is not quite clear. It stems from an uncritical use of such words as "think", "conceive", "imagine", etc. One interpretation is logical and consists in recognising that the sentence "the predicate 'is God' is non-empty" is necessarily true. The second reading is more psychological and suggests that it is impossible to conceive that "is God" is empty. This leads to the conclusion of conceiving that the predicate "is God" is non-empty, which is a necessary conclusion. However, passing from the necessity of conceiving (thinking, understanding, imagining, etc.) that some $a$ exists to the necessity of its existence can be considered problematic. Accepting this link means that the conceivability (possibility of conceiving) of something is equivalent to its existential possibility and provokes at least two objections; namely, firstly, that of psychologism and, secondly, that human acts of conceiving differ with respect to subjective circumstances and cannot measure what is objective, possible or necessary. Consequently, one, Anselm for instance, can point out that any person arguing for the emptiness of the predicate "is God" plays the role of the Fool.

Fortunately, both interpretations can be reconciled by the reduction of conceivability to consistency. This move equates possibility and consistency, and renders psychological language as a rhetorical ornament 
to a concrete argumentation, for example, concerning the Lost Island. Contemporary formalizations of Anselm's proof tend to be completely free of such psychologism. One of such formalizations is as follows (I employ proposals made by the late Jerzy Perzanowski; his paper is unpublished and preserved as a draft). Perzanowski starts with a reconstruction of the reasoning proposed by Charles Hartshorne. It is based on two axioms:

(a) If a being is the most perfect, its existence is necessary;

(b) the existence of the most perfect being is possible (Leibniz' lemma). Using modal system S5, we can obtain:

(c) The most perfect being exists.

Perzanowski simplified Hartshorne's argument by proving (b) in a stronger modal logic, equating truth and necessary truth. Moreover, this logic proves (this is another version of the Leibniz lemma)

(d) if the most perfect being is possible (its existence is possible), it is necessary (its existence is necessary).

Hence, via modus ponens, we have

(e) the most perfect being exists as necessary (necessary existence implies existence).

The last step ends Perzanowski's reconstruction.

What could contemporary Gaunilo say for Perzanowski's argument? Certainly, he cannot limit himself to arguments advanced by his mediaeval predecessor, because Anselm's followers elaborated new weapons. However, the situation of modern Gaunilo is not hopeless. If the matter concerns (a), one might observe that it is a conditional assertion having an existential antecedent. Hence, any further application of this axiom essentially depends on truth of the sentence "the most perfect being exists". If (b) is applied in proving that the most perfect being exists, the entire argument is burdened by petitio principii. This is quite evident if we consider the equivalence (f); the most perfect being exists if and only if the most perfect being exists and it is possible.

However, (f) is trivial because the sentence " $a$ exists" entails "it is possible that $a$ exists". As far as the issue concerns Perzanowski's simplification, the success of his main move based on (d) requires a very strong modal logic (the logic of strong rationalism). Although the scope of the term "logic" is conventional to some extent, one can express some serious doubts about whether logic should lead to existential consequences that are so strong. Personally, I would prefer to say that the proof of the Leibniz lemma and 
further steps of the entire argument proceed in the context of some formal theory involving modal concepts and relations between them, and that this theory is not purely logical. Nevertheless, the fact that Anselm's argument can be presented via a precise formal machinery shows the power of formalization applied to concepts of rational theology or theological ontology.

Since, according to Leibniz, possibility is logically equivalent to consistency, (d) can be rendered as

( $\mathrm{g}$ ) if the most perfect being is consistent, its existence is necessary.

Let the letter $B$ denote the predicate "is the most perfect being". Assume that $B$ is introduced by some consistent set $K$ of sentences. By the Gödel-Malcev completeness theorem (a set $X$ of sentences has a model if and only if this set is consistent), $K$ has a model. This assumption metamathematically guarantees that $K$ is non-empty. One can be even tempted to say

(h) if a set of sentences has a model, it possesses it necessarily (it is impossible that the set in question has no model).

However, this last assertion requires additional constraints (see below). The way in which $K$ is given as defining the item conceived as greater than any other being, is very important. First of all, the phrase "the conceived item" means "the item described by a set of sentences". Secondly, according to the common opinion, the most perfect being (MPB, for brevity) is introduced by the maximalization procedure. Metalogically speaking, it consists in the identification of MPB with a collection of perfections (omniscience, omnipotence, the greatest goodness, immutability, infinity, etc.); existence belongs to perfections. Assume that $\mathrm{KO}$ is a initial consistent collection of perfection. It might be maintained that application of the Lindenbaum maximalization theorem (every consistent set of sentences has a maximally consistent extension) provides an argument for generating the adequate set $K$. However, the Lindenbaum extensions are not unique. More specifically, if $X$ is a consistent set of sentences, it has more than one (in fact, there are infinitely many) maximally consistent extensions. Every such extensions $E$ has a model (a possible world) in which elements of $E$ are true. Moreover, since these sentences cannot be false in this model, they must be true in it as well. Note that the relativisation to a specific model is crucial.

Let us apply these observations to the set $K 0$ and $K$. Clearly, the former set has several different maximally consistent extensions, including $K$, 
as their part; in fact, $K$ itself is not maximal, but this is a minor point. Metamathemathical observations about $K$ are not sufficient to demonstrate that this set is true in every possible world. Note that we could consider $K$ as a body of absolute necessities (necessary truths), that is, sentences true in every model. It is obvious now that necessity of truth with respect to a specific model is not absolute, but just relative, because a sentence true in one model can be false in other possible worlds. Moreover, there is no a priori reason to refer to one and only one initial set $K 0$ of perfections. One could ask, for instance, why the greatest goodness or immutability, but not changeability or goodness directed to people deserving it to some degree, should be regarded as prima facie perfections. Typically listed perfections are recommended by Christian (or other similar) theology, but it is only a religious argument, not a logical one. Thus, contemporary versions of Anselm's ontological proof do not show that $B$ is not empty in virtue of logical necessity. Further, one cannot demonstrate independently of the assumptions of a given monotheistic theology that the denotation of $B$ is unique.

If we apply a similar technique to any consistent collection of anti-perfections (that is, pointing out the lack of perfections in the ordinary or theological sense), it is easily provable by the dual logic and metamathematics (it takes falsity as the distinguished value) that there is a being such that nothing lesser can be conceived. We can interpret this being as the Absolute Evil ( $\mathbf{A E}$, for brevity). If we entirely omit the ordinary or religious meaning of perfection, AB is a maximal being, because it is constructed by a similar maximalization strategy as employed in the case of the denotation of $B$. There is no reason, at least no logical reason, to maintain that $\mathrm{AE}$ is less real than MPB or the Christian God. This leads to a Manichean theology with its perennial battle between the forces of Goodness and Evil, or even a radicalized Marcionic heresy on which the world presents itself as an emanation of the personified Evil, in particular, deceiving people in order to make them suffer more. The theist could presumably answer that the metamathematically phrased ontological proof is enough for demonstrating the existence of MPB, let's say a god of philosophers having properties not entirely coherent with Christian theology. This being is necessary and thereby existing. However, this standpoint is not correct, even if we agree that some perfections actually occur in our world. Lindenbaum's maximalization procedure does not imply that there exist maximal perfections in the sense of Anselm and his followers. Although people know something, 
can do something, or behave properly, these facts do not entail that there is a being (subject) which realizes these properties in the most maximal manner. Thus, there are models in which there occurs no MPB. In fact, some maximally consistent extensions of $K 0$ contain the sentence "there exists the MPB, according to a given specification of perfections", but this sentence is false in other extensions. Since we do not know which model represents our universe, we can only say that the gods of philosophers (and theologians as well) exist in some possible models.

The contemporary setting of the Gaunilo/Anselm exchange could be rendered in such a way:

Anselm. I proved that there is a model in which the predicate $B$ is not empty. Gaunilo. That's right, but your strategy allows me to prove that an arbitrary consistent predicate is not empty as well.

Anselm. You overlooked that the set of sentences determining the denotation of $B$ is necessary (consist of necessary truths). This means that this denotation exists (is a perfection), but references of your predicates exist accidentally. Consequently, you cannot deny the existence of the denotation of $B$ without contradicting yourself.

Gaunilo. You are mistaken, because you do not distinguish absolute and relative necessity. Although you correctly demonstrated that the set $K$ used for the characterization of the predicate $B$ is true in some model $\mathbf{M}$, the existence of an item satisfying the conditions in question is a perfection, but only with respect to $\mathbf{M}$. There are no obstacles to treat my predicates, for instance, related to the Lost Island, in the same way. Moreover, I can prove that there are many maximally, but mutually different, perfect beings.

Gaunilo was a faithful Christian and had no doubts concerning God's existence. However, although he could consider atheists as unreasonable people, he said something important on behalf of the Fool, namely that Anselm did not prove what he intended to demonstrate by his ontological argument. According to earlier comments, Gaunilo's arguments can be sharpened by observing that the assertion that God does not exist can be consistently added to any set of statements about the empirically accessible world; clearly, the sentence "God exists" transcends such sets. Thus, Anselm was unfair, when he qualified unbelievers as foolish. 